\title{
War on Drugs: The Readability and Comprehensibility of Illegal Drug Awareness Campaign Brochures
}

\author{
Fermina Bernabe Vergara \\ University of Santo Tomas, Philippines \\ fbvergara@ust.edu.ph \\ Rachelle Ballesteros-Lintao \\ University of Santo Tomas, Philippines \\ rblintao@ust.edu.ph
}

DOI: $\underline{\text { http://doi.org/ 10.36892/ijlls.v2i4.412 }}$

\begin{tabular}{|c|c|}
\hline $\begin{array}{l}\text { Received: } \\
\text { 03/11/2020 }\end{array}$ & $\begin{array}{l}\text { Abstract } \\
\text { Information communicated and produced by the government is essentially }\end{array}$ \\
\hline $\begin{array}{l}\text { Accepted: } \\
\text { 15/12/20202 }\end{array}$ & $\begin{array}{l}\text { fundamental as the government is set and deemed as a reliable and a credible } \\
\text { source of information. This study assessed the readability, comprehensibility, } \\
\text { and document design of two brochures on prohibited drugs awareness, which } \\
\text { were produced and distributed by the Dangerous Drugs Board (DDB), a }\end{array}$ \\
\hline $\begin{array}{l}\text { Keywords: } \\
\text { comprehensibility; } \\
\text { document design; } \\
\text { drug addiction; plain } \\
\text { language; } \\
\text { readability }\end{array}$ & $\begin{array}{l}\text { government agency that is responsible in instituting policies about the use of } \\
\text { illegal drugs in the Philippines. Using both qualitative and quantitative } \\
\text { methods, a total number of } 120 \text { participants comprised of students, those } \\
\text { employed, the unemployed, and drug patients from a rehabilitation center } \\
\text { answered two 10-item multiple choice questionnaires and Likert scales to } \\
\text { assess and evaluate the comprehensibility and document design of the two } \\
\text { brochures. Using the Coh-Metrix tool to analyze the readability of the two } \\
\text { brochures, results showed that the two existing brochures were not that } \\
\text { readable with the huge discrepancy of the readability levels of the docments } \\
\text { against the 9-10 normative values of the reading tool utilized. The results of } \\
\text { the participants' scores which were categorized as instructional or assisted } \\
\text { level exhibited that the two brochures were not that comprehensible. Lastly, it } \\
\text { was found that the designs of the documents were poor as some violations like } \\
\text { small font size, pixelated pictures, and non-observance of color schemes were } \\
\text { present. This paper argues that government agencies should produce } \\
\text { information brochures that are patterned to the standards of Plain Language } \\
\text { Movement in order to help the lay people grasp important information such as } \\
\text { drug awareness. }\end{array}$ \\
\hline
\end{tabular}

\section{INTRODUCTION}

Language is one of the most important foundations of human interactions as people make use of language, whether verbal or non-verbal, to express thoughts, ideas, opinions, and feelings(Al-Ghamdi, Almansoob, Alrefaee, 2019). It is also in and with the use of language that people question, describe, explain, and perform actions in the social context (Francis \& Hester, 2004). People also rely heavily on language in their daily interactions to communicate a number of important information like news, announcements, warnings, and other pertinent information. However, language can also be an instrument to create a gap and problem in human interactions that greatly affect those involved in such social functions.

For instance, in the field of law, contracts, and other legal documents are found to be difficult to understand by non-experts of the law or lay people because the language that is 
used in these types of documents is complex in structure and highly technical in terms of vocabulary (Mykhailova, 2012; Tiersma, 1999; Williams, 2004). Likewise, several challenges confront the field of health in terms of how language is used in different aspects. For instance, a prescription reads "instill one drop, OU, 2x daily" (Trudeau, 2016, p. 37), but a patient may not understand that 'OU' means two eyes. In fact, several studies (Bradley, Li Wan Po \& Singleton,1994; Hannan, Trivedi \&Trivedi, 2014) reported that non-prescription labels of over-the-counter (OTC) medicines were found to have lengthy texts and technical vocabularies. As a consequence, patients were not able to perform the proper prescribed medication affecting their health and lives.

The complexity of the language as used in different kinds of texts burdens the people who use the documents, which is why many experts in different fields (Cutts, 2009; Schriver, 1997; Tanner, 2000; Trudeau, 2016 \& Williams, 2004) have called for the simplification of language and appropriation of document design as used in different documents to help laypeople understand the texts that they read and use.

\section{Plain Language and the Plain Language Movement}

Several experts in different fields like law, health, business, and government have advocated the use of a plain language, or Plain English for laypeople to find what they need, understand what they read, specifically with texts that are important, and use what they find to meet their needs.

Plain language, which is also called Plain English, is a kind of communication understood by readers or audiences the first time they read a given material (Plain Language, n.d.). It has also been emphasized by the National Institutes of Health (NIH) in the United States that "plain language is not unprofessional writing or a method of 'dumbing down' or 'talking down' to the reader," (para. 1) and that clear writing tells the readers what they exactly need to know and do without having to use unnecessary expressions or words that create communication barriers (NIH, n.d.).

Plain language experts have emphasized and promoted the use of a language which contains simple words and is devoid of convoluted sentence structures and unnecessary words in order for readers of a particular text to understand the message clearly. These characteristics of plain language reflect the nature of text readability. Furthermore, plain language personalities also give importance to document comprehensibility, ensuring readers to understand the document easily; and, document design that allows readers to easily navigate, see, and comprehend or understand a text that they read.

\section{Readability}

Readability, which is one of the most important aspects of any produced technical documents, must conform to the reading level and literacy of the target audiences. Readability has its two main sources of definition. One is related to document design which is concerned with document features like fonts, line spacing, font size, typeface, and the like. The other definition is rooted from the linguistic aspect as readability has been regarded as the ease by which readers can read a specific text (Marnell, 2008).

Readability is measured through readability formulas based on traditional methods and cognitive science. For traditional methods, some of the readability formulas include the Flesch-Kincaid, Lexile Framework, and Dale-Chall Readability formulas. These traditional readability formulas "are simple algorithms that measure text readability based on sentence length and word length" (Allen, Crossley \& McNamara, 2011, p. 87). Although traditional methods are favored by many because they are easy to use, several scholars have criticized and argued against them because of their ineffectiveness to indicate a reader's comprehensibility, and for failing to align the cognitive processes that are involved in text 
comprehension closely (Crossley, Duffy, McCarthy, \& McNamara, 2007; McNamara \& Magliano, 2009). Because of those criticisms, many researchers sought to evaluate and analyze texts through cognitive-based models. Thus, several methods and variables have been developed based on cognitive theories (Benjamin, 2012).

It is important to note that the major tools and variables used in cognitive-inspired readability measures are propositions and inferences (Kintsch \& van Dijk, 1978 cited in Benjamin, 2012), and latent semantic analysis.

Propositions and inferences were incorporated by Kintsch and van Dijk (1978 as cited in Benjamin, 2012) in their analysis of text difficulty for text comprehension. Propositions are the "brief meaningful units that do not take into account information like tense, voice, or aspect" (Graesser et al., 1997, as cited in Benjamin, p. 70). On the other hand, inferences are made by readers when a text is highly cohesive, but for a text to be considered coherent and cohesive, there must be an "argument overlap among successive sentences" (Benjamin, p.70).

Another tool used in cognitive-based readability measures is the latent semantic analysis (LSA). Benjamin (2012) characterizes LSA as an automated tool representing text content as "a vector in a semantic space" (p. 70). She also adds that LSA analyzes semantic relatedness between texts, examines the indirect relationships of words in a given context, and it has been used to match the readers to suitable difficult texts and to determine the cohesiveness of a given text.

\section{Comprehensibility}

Comprehensibility pertains to the capacity of a reader to understand a text that he or she has read (Omanson, 1985; Jones, 1997; Yassin, Razak, \& Maasum, 2019). While readability is text-centered, comprehensibility focuses more on the reader of the text; thus, it is reader-centered. There are two principal levels of cognitive scheme for understanding a text as presented by Kintsch (1988, as cited in Lintao \& Madrunio, 2015). The first level involves readers extracting details and ideas present from the text, and the second level concerns readers relating their own background knowledge or schema to the text that they have read.

One of the methods to measure comprehensibility is through the use of multiplechoice questionnaire (MCQ). It is a kind of test that includes an introductory question or incomplete statement that appears before the options or answers consisting of the correct option and distractors (Bertrand \& Cebula, 1980; Kehoe, 1995) that serve as incorrect choices.

MCQ has been valued and used for many years to assess learning and understanding of lessons and texts because of its "absolute objectivity and the precise understanding of the text it demands" (Strathmann, 1979, p. 304). Additionally, this kind of test is more effective for measuring higher cognitive processes (Bertrand \& Cebula, 1980).

\section{Document Design}

The way a document looks like from the readers' perspective gives them an impression of what the text is all about. In the same manner, the design of these texts and documents can also affect readability and comprehensibility.

Schriver (1997) defines document design as "the field concerned with creating texts that integrate words and pictures in ways that help people achieve their specific goals for using texts" (p. 10) in different domains like home, school, and even in the workplace.

Felker, Pickering, Charrow, Holand, and Redish (1981 as cited in Lintao, 2015) highlight the role of document design as very important in the overall comprehensibility of spoken or written legal documents. The centrality of document design has been likewise put forward by Cutts (2009) in noting that document design is a fundamental part of creating texts that can be comprehensible to people. The Plain Language Movement in the United 
States has also set that an important part of creating effective communication among readers is the design of any material (Plain Language, n.d.).

According to Tinker (1963 as cited in Schriver, 1997), legibility concerns the typographic features which aid people to read a text with ease. Doing so enables readers to comprehend the text quickly and effortlessly, and with clear understanding of what they are reading. Different aspects serve as keys to make a document legible:

a. Type size (point size)- is measured from the top of the highest ascender or the capital letter to the base of the letters such in the case of ' $j$ ' and ' $y$.' It is measured in points in which 6 to 72 points are generally used.

b. Typeface- refers to the complete set of characters, punctuations and symbols sharing the same design, and it has two basic styles; namely, serif and sans serif. On the one hand, serif refers to the "line or curve that finishes off the end of a letterform" (Schriver, 1997, p. 255) which is considered useful because it helps the readers' eye to distinguish each letter. On the other hand, sans serif is characterized by the lack of serif which provides a "uniform, clean, and modern appearance" (p. 256) in any document that allow for good visual distinctions among the other parts of the text.

c. Leading-the amount of a vertical space in between the lines of type. For printed documents to be easily read, leading should add approximately 20 percent to the typeface's point size.

d. Line length (column width) -refers to the distance between the left and right margins of the type.

e. Justification- refers to the "visual display of the left and right margin" (Schriver, 1997, p. 269). In utilizing justification, Campbell, Marchetti, and Mewhort (1981 as cited in Schriver, 1997) note that a right-justified text with equal horizontal spaces between words produce a faster reading speed than a 'river' condition justification in which there is an existence of unequal spaces between words.

Document design does not only concern the typographical features, but as mentioned earlier, the interplay of words and pictures are of significant consideration as well.

\section{The Philippine Drug Situation}

The illegal drug situation in the Philippines has been given more emphasis and focus since President Rodrigo R. Duterte was sworn into office in 2016. Under his administration, President Duterte promised to eradicate the increasing rate of crimes that are considered as adverse effects of illegal drug addiction through his anti-illegal campaign known as "War on Drugs."

The Philippine Drug Enforcement Agency (PDEA), the official government agency responsible for the investigation, enforcement, and implementation of combating illegal drug activities in the country, has estimated that there are about 4.7 million drug personalities in the Philippines, thus, calling this issue as a national security threat (Cabrera, 2017). Furthermore, the top three illegal drugs abused by the Filipinos are 1) Methamphetamine hydrochloride or shabu; 2) Cannabis sativa or marijuana; and, 3) Methylenedioxymethamphetamine (MDMA) or ecstasy (PDEA, 2012; DDB, 2013).

Because of the issues relating to illegal drug abuse that affect the welfare and health of the citizens, and the society in general, Philippine government agencies like the Dangerous Drugs Board (DDB) have been tasked to exert efforts like "anti-drug advocacies and information campaigns" (Dangerous Drugs Board, 2013, para. 1) which include drug seminars and preventive programs, and the distribution of drug awareness brochures and posters to reduce and eliminate the use of illegal drugs.

According to Barbers (as cited in Quismoro, 2018), being well-informed about illegal drugs activities is the best way to combat illegal drugs. However, with the increasing number of illegal drug users and crime rates related to illegal drug use (Ranada, 2016), it is now 
important to look into the preventive programs of the government, particularly the DDB to combat illegal drug activities.

One of the means that the DDB uses to implement its preventive education against illegal drug addiction is through the distribution of brochures that contain pertinent information about illegal drugs to the general public. Brochure distributions are one of the important means of DDB to make people aware and conscious of the harmful effects of illegal drugs. More importantly, the government has collaborated with local government units (LGUs) and other executive departments like the Department of Education (DepEd), and different non-organizational sectors like Bantay-Bayan to promote the anti-illegal drug (AID) campaign (Philippine Drug Enforcement Agency, n.d.). In line with this, DepEd has strengthened AID campaigns through the establishment of National Drug Education Program (NDEP) in schools.

Information campaigns such as the illegal drugs awareness brochures are vital instruments in informing the public about what drug addiction is, its effects, and its risks. It is also noteworthy that language can be a crucial instrument in communicating this kind of information regarding illegal drug addiction which requires the public people to know about it and to act on it, most especially that it does not only affect a specific individual user of an illegal drug, but it can also affect the society in general. The use of simple and understandable language (i.e., plain language), and appropriate document design are equally essential in conveying important information to the public people.

Therefore, this study sought to answer the following research questions:

1. How readable are the illegal drug awareness brochures distributed by the Dangerous Drugs Board?

2. How comprehensible to the target readers are these illegal drug awareness brochures?

3. What linguistic features could account for the ease or difficulty in understanding the documents?

4. What document design features could account for the ease or difficulty in understanding the documents?

\section{METHODOLOGY}

This study employed qualitative and quantitative methods as its research design in which the readability, comprehensibility, and document design were analyzed and assessed. The qualitative design was employed in analyzing the comprehensibility of the document through 10-item multiple choice questionnaires, whereas the quantitative design was employed in analyzing the readability and document design using Coh-Metrix tool and mean variance, respectively.

\section{Research Participants}

A total number of 120 respondents comprised of 30 students, 30 employed, 30 unemployed, and 30 rehabilitation patients, participated in this research. This study covered all groups of document users from all walks of life as these people are the target audience or readers of the two existing brochures that should be understood and used by them. The criteria that were considered in choosing the participants were the following: ages 15 to 65 as this is the target age range of the two existing brochures as mentioned by DDB personnel; high school and college students; employed in a private company or in the government; and have at least a basic knowledge of the English language in order to produce genuine results since the two brochures were written in English. 
As regards the basic knowledge of English, this was determined through selfperception informal survey by which the student, employed and unemployed participants were asked if they can read, write, speak or understand English. The rehabilitation patients group was initially screened and determined by the head counselor of the rehabilitation center who basically knew the communication ability of the respondents.

There were 71 male and 49 female participants whose ages range from 16 to 65 years old. For the students, there were eight high school students and seven college students coming from public schools. From the private schools, there were nine college students and six high school students. The group of the employed was composed of 18 participants working in the government, and 12 participants working in a private company. For the rehabilitation patients, all of them were male whose ages ranged from 22-64 years old.

In order to have a clear overview of the participants' general profile, Table 1 is presented below:

\section{Table 1. Demographic Information of the Participants}

\begin{tabular}{|c|c|c|c|c|c|c|c|c|}
\hline \multicolumn{3}{|c|}{ Student } & & \multicolumn{2}{|l|}{ Employed } & \multicolumn{2}{|c|}{ Unemployed } & \multirow{2}{*}{$\begin{array}{l}\text { Rehab patients } \\
\text { All Male (30) }\end{array}$} \\
\hline Public & & Private & & Government & Private & Female & Male & \\
\hline College & 8 & College & 9 & 18 & 12 & 13 & 17 & \\
\hline H.S & 7 & H.S & 6 & & & & & \\
\hline Female & 15 & & & Female & 21 & & & \\
\hline Male & 15 & & & Male & 9 & & & \\
\hline
\end{tabular}

\section{Study Corpus}

Out of the six brochures that are readily available and distributed by Dangerous Drugs Board to the public, two brochures that deal with information regarding shabu and marijuana were analyzed in this study. These two brochures were chosen to be studied because shabu and marijuana are the top illegal drugs reported to be abused by Filipinos.

\section{Research Instruments}

Two 10-item multiple choice questionnaires, which were expert-validated, were answered by the participants to measure the comprehensibility of the documents. Items that were included on the questionnaires were based on the information presented on the two existing brochures, and they were comprised of lower-level and higher-level questions.

In evaluating the document design features of the existing brochures, two Likert scales were answered by the participants. These Likert scales contained the criteria that were adapted from the ClearMarks Awards. The ClearMarks Awards is an organization sponsored by the Center for Plain Language which aims to help government and businesses produce materials which are clear and understandable for readers the first time they read such materials.

\section{Research Procedure}

A. Data Collection

Two brochures on shabu and marijuana were collected personally from the Dangerous Drugs Board. These brochures were chosen as shabu and marijuana are the top two illegal drugs abused by Filipinos. 
B. Test Formulation

A 10-item multiple-choice questionnaire about the information found in each brochure for the comprehension test was formulated and was validated by three experts. An 11-item Likert scale for the document design evaluation was also prepared following the ClearMarks Award criteria. The test questionnaires and Likert scale were improved based on the suggestions and comments of the three experts.

\section{Pilot Testing}

The questionnaires and Likert scales were pilot tested to 12 pilot-test respondents. It took approximately 45 minutes for the respondents to read the brochures and answer the questionnaires and Likert scales. No problems were observed in the questionnaires during the pilot test administration. However, directions on how to indicate answers on the answer sheet were emphasized and highlighted as some respondents answered on the questionnaires. The Likert scale results were sent to the statistician for testing the internal consistency and reliability. There was no need to delete or change the items from the Likert scale evaluation as these items were internally consistent and reliable.

D. Actual Testing

In the actual test, the background of the study was introduced and instructions were given to the participants. Participants were asked to read the brochure about shabu and marijuana, and they were asked to answer the multiple-choice questionnaires. When the participants finished accomplishing the comprehension tests, two sets of Likert scale- one for the shabu brochure and one for marijuana brochure- were immediately given for the evaluation of the document design of the two brochures. The test took approximately 30 minutes. An interview with 16 participants after the test was conducted to determine the linguistic and document design features that accounted for difficulty in understanding the brochures. Twelve participants from the groups of students, employed, and unemployed volunteered for the interview, while the remaining four from the rehabilitation patients group were selected by their head councilor.

E. Analysis of Data

For the readability of the data, a typewritten format of the two brochures was inputted on the Coh-Metrix web tool, and the results yielded by the online tool was downloaded and analyzed. The scores of the comprehension test were analyzed using the relative frequency distribution and were subjected to analysis using the difficulty index item analysis. Mean variance was utilized to analyze the participants' evaluation of the document design elements of the brochures.

\section{Data Analysis}

Three units of analysis, namely, computational analysis, descriptive analysis, and linguistic analysis were employed in this study.

\section{Readability}

Coh-metrix computational tool which was developed by McNamara, Louwerse, and Cai in 2004 was employed in this study. This computational tool is a web-based tool developed through the advancement and breakthroughs of corpus linguistics, computational linguistics and others (Crossley et al, 2008 as cited in Lintao, 2015).

This computational tool measures different characteristics of texts that reflect coherence wherein there were 11 major groups, namely:

1) Descriptive Indices- measure the descriptions present on the texts such as number of paragraphs, sentences, words, etc.

2) Text Easability Principal Component Scores- provide a more complete idea about text ease and difficulty emerging from the linguistic characteristics of texts. 
3) Referential Cohesion- calculates the overlap in content words between local sentences, or coreference.

4) Latent Semantic Analysis- provides the measures of semantic overlap between sentences and paragraphs.

5) Lexical Diversity- analyzes the variety of unique words occurring in the text in relation to the total number of words.

6) Connectives- identify all types of connectives used in the text as these play important role in creating cohesive links between ideas and clauses.

7) Situation Model- refers to the level of mental representation of a text that involves much more than the obvious or explicit words.

8) Syntactic Complexity- evaluates the features of the syntax present in the texts like counting the number of words before the main verb for left embeddedness.

9) Syntactic Pattern Density- estimates the incidences and relative frequencies of noun phrases, verb phrases, adverbial phrases, and prepositional phrases in a certain text.

10) Word Information- computes the incidences of the parts of speech like nouns, verbs, adjectives, adverbs, and prepositions used in the text.

11) Readability- calculates the readability features of the text like its reading ease, reading grade level, and the second language (L2) readability level.

It can be accessed on www.tool.cohmetrix.com.

The numbers generated by the Coh-metrix tool were compared with the Degrees of Reading Power (DRP) normative values provided by Cai, Graesser, Mccarthy, and McNamara (2014).

Table 2. DRP scores for each grade band of TASA passages

$\mathrm{N}=$ number of passages *College-Career Ready

\begin{tabular}{llllll}
\hline $\begin{array}{l}\text { Grade } \\
\text { Band }\end{array}$ & N & Mean DRP & $\begin{array}{l}\text { Std. } \\
\text { Deviation }\end{array}$ & Min. DRP & Max. DRP \\
\hline K-1 & 300 & 43.2465 & 2.33841 & 35.00 & 45.99 \\
\hline $\mathbf{2 - 3}$ & 600 & 48.8362 & 1.45713 & 46.00 & 50.99 \\
$\mathbf{4 - 5}$ & 600 & 53.3161 & 1.44334 & 51.00 & 55.99 \\
$\mathbf{6 - 8}$ & 900 & 59.1749 & 1.34791 & 56.00 & 60.99 \\
$\mathbf{9 - 1 0}$ & 600 & 62.2777 & 0.90323 & 61.00 & 63.99 \\
\hline $\mathbf{1 1 - C C R *}$ & 900 & 67.4324 & 3.10350 & 64.00 & 85.80 \\
\hline
\end{tabular}

As stated by the Preventive Education, Training and Information Division (PETID) of the DDB, the two existing brochures on shabu and marijuana are deemed to be read by the general public consisting of high school and college students, employed, unemployed, and rehabilitation patients. This study used the 9-10 grade band as the high school participants in this study were from Grade 10, and that this level serves as a baseline level in targeting the prospective participants of this study.

\section{Comprehensibility}

In order to describe, analyze, and summarize the features of the data, descriptive statistics was utilized. Particularly, relative frequency distribution or percent frequency was employed as a statistical tool to describe and analyze the comprehension scores of the participants. The percent frequency is expressed following this formula: 
rfor $\% f=\frac{f}{n} \cdot 100$

Where $\mathrm{f}=$ the frequency

$\mathrm{n}=$ number of cases

To classify the percentage scores of the participants into different comprehension levels, the categories provided by Dubay (2014) were utilized.

Table 3. Level of Comprehensibility for Multiple Choice Test

\begin{tabular}{lll}
\hline Purpose or Level & Score & Description \\
\hline Unassisted Reading & $70 \%$ above & No assistance is needed in understanding the text. \\
Instructional/Assisted & $50-60 \%$ & An assistance is needed to understand the text. \\
Frustration Level & Below $50 \%$ & The text is not understood by the reader. \\
\hline
\end{tabular}

To measure the proportion of the participants who answered each item of the questionnaires correctly, item analysis, particularly the difficulty index item analysis was utilized. This was analyzed using the formula provided below:

Where $\mathrm{p}=$ difficulty index

$$
p=\frac{C}{N}
$$

$\mathrm{C}=$ number of participants who got the item correct

$\mathrm{N}=$ total number of participants who answered the test

A verbal interpretation of the difficulty index is presented on the following table:

Table 4. Verbal Interpretation of the Difficulty Index

\begin{tabular}{ll}
\hline Range & Interpretation \\
\hline $0.67-1.0$ & Easy \\
$0.33-0.66$ & Average \\
$0.00-0.032$ & Difficult \\
\hline
\end{tabular}

Document Design

Mean variance was utilized in this study to analyze the results of the participants' evaluation of document design. Answer for each item was added and divided by the total number of participants. A verbal interpretation of the results of the evaluation of the participants is presented below:

Table 5. Verbal Interpretation for Evaluating the Results of the Two Existing Brochures

\begin{tabular}{ll}
\hline Range & Interpretation \\
\hline $1-1.74$ & Poor \\
$1.75-2.49$ & Not Good \\
$2.5-3.24$ & Good \\
$3.25-4$ & Very Good \\
\hline
\end{tabular}

\section{RESULTS AND DISCUSSION}

This section of the study covers the significant results and interpretations that relate to the readability, comprehensibility, and document design features of the two existing brochures on shabu and marijuana. 
The Readability of the Two Anti-Illegal Drugs Awareness Campaign Brochures

Table 6. Measures of Readability of the Two Brochures and the 9-10 normative Values

\begin{tabular}{lccc}
\hline Description & Score for Shabu & Score for Marijuana & 9-10 Normative Values \\
\hline Flesch Reading Ease & 36.373 & 44.557 & 62.299 \\
Flesch-Kincaid Grade Level & 10.876 & 9.575 & 10.242 \\
Coh-Metrix L2 Readability & 2.907 & 9.560 & 13.967 \\
\hline
\end{tabular}

Table 6 shows the readability measures generated by the Coh-Metrix tool in which a big discrepancy in the Flesch Reading Ease can be observed between the 9-10 normative values and the scores generated by the two brochures. For the brochures on shabu and marijuana, the values were lower than the 9-10 normative values. Likewise, in terms of the L2 readability measure, the brochure on shabu and marijuana scored lower that the CohMetriz L2 Readabilty index.

These results only show that the two existing brochures on shabu and marijuana are not that readable. First, in terms of the Flesch Reading Ease, values that are higher than the normative value are considered easy to read, however, the generated scores of the two brochures are lower than the normative value. Second, in terms of the L2 readability index, the results indicate that for second language users, the brochures are not that readable for them since the result yielded by Coh-metrix is lower than the 9-10 normative value. It should be noted that higher the L2 readability measure is from the normative value, the more readable these two existing brochures are.

In terms of the word information, four indices with significant results are presented below in Table 7 .

Table 7. Word Information Measures of the Two Brochures and the 9-10Normative Values

\begin{tabular}{lccc} 
Description & Shabu Brochure & Marijuana Brochure & $\begin{array}{l}\text { 9-10 Normative } \\
\text { Values }\end{array}$ \\
\hline Noun Incidence & 364.865 & 32.645 & 240.713 \\
Second Person Pronoun Incidence & 0 & 26.052 & 7.034 \\
Familiarity for Content Words & 555.566 & 562.190 & 570.105 \\
CELEX Word Frequency for & 1.784 & 1.945 & 2.208 \\
Content Words & & &
\end{tabular}

In this table, results from the two brochures garnered very high scores as compared to the acceptable normative value in terms of noun incidence. The brochure on shabu, generated124.152 (364.865-240.713) score more than the accepted normative value, while the marijuana brochure yielded 81.932 (322.645-240.713) more than the accepted normative value as well. For the second pronoun incidence, the mean normative value for the 9-10 grade band is 7.034; however, the brochure on shabu garnered an absence of second person pronouns. Meanwhile, the brochure on marijuana scored 26.052 which is higher than the accepted normative value. In terms of familiarity for content words, two brochures generated lower than the accepted normative value with the brochure on shabu having a score of 555.566, and the brochure on marijuana garnering a score of 562.190. For the CELEX word frequency for content words, both the brochures on shabu and marijuana accumulated scores lower than the accepted normative value. For the brochures on shabu and marijuana, they scored 1.784 and 1.945 , respectively as against the 9-10 normative value of 2.208.

The word information results only signify that these features contribute to the low readability of the existing brochures. The high incidences of nouns of the two brochures as shown in the table can be attributed to the low readability of the two brochures as the ideal result for noun incidence should be lying at 240.713 or below. Additionally, results yielded 
for the word frequency of content words on the brochures on shabu and marijuana were lower than the normative value which means that there is a low word frequency for content words present in the two existing brochures. It is noteworthy that frequency of words in a particular text is very important as this reflects the world knowledge of the target audiences (Beck, McKeown \& Kucan, 2002; Cai et al, 2014 \& Perfetti, 2007). Similarly related to word frequency is word familiarity in which readers of a text are more familiar with words that are highly frequent. From the results, it can be observed that the familiarity level of the two brochures is lower than the accepted value which means that the target audience of the two existing brochures are not that familiar with the content words present in the two texts. Cai et al. (2014) state that when there are uncommon words present in the text, the level of text difficulty is expected to increase.

In addition to the presented results above, one aspect from the syntactic pattern density has garnered significant results. The agentless passive voice density generated a score of 11.261 for the brochure on shabu, and 12.024 for the brochure on marijuana.

The use of passive voice in the two existing brochures is another factor for the low readability account of the results yielded by the Coh-Metrix tool as this is more difficult for people to process and comprehended (Brown \& Hanlon, 1970 as cited in Filby \& Olson, 1971).

The readability of the two existing brochures using a text-based measure is an important facet to consider in creating crucial information campaigns such as these. Of significant importance as well is the comprehensibility of the document.

\section{The Comprehensibility of the Two Brochures to the Target Audience}

The mean score of all of the participants for the brochure on shabu is $51 \%$, while their mean score for the brochure on marijuana is $55.58 \%$. These results only show that the two existing brochures were found to be not that comprehensible to all of the participants since the overall mean scores were categorized under the instructional or assisted level. It should be noted that in order for the brochures to be comprehensible, readers should be able to understand these texts without any assistance. In other words, they should be capable of understanding the texts independently.

\section{The Comprehensibility of the Two Brochures to Each Group of Participants}

\section{Table 8. Mean Comprehensibility Scores of the Participants}

\begin{tabular}{|c|c|c|c|c|}
\hline Participants & $\begin{array}{c}\text { Mean Score } \\
\text { (Shabu) }\end{array}$ & $\begin{array}{l}\text { Mean Score } \\
\text { (Marijuana) }\end{array}$ & Level & Description \\
\hline Students & $64.3 \%$ & $65 \%$ & Instructional & $\begin{array}{l}\text { Needs assistance in } \\
\text { understanding the text }\end{array}$ \\
\hline Employed & $45.7 \%$ & $48 \%$ & Frustration & Not understood by readers \\
\hline Unemployed & $39 \%$ & $46.7 \%$ & Frustration & Not understood by readers \\
\hline Rehab Patients & $55 \%$ & $63 \%$ & Instructional & $\begin{array}{l}\text { Needs assistance in } \\
\text { understanding the text }\end{array}$ \\
\hline
\end{tabular}

Table 8 presents the mean percentage scores of each of the groups of the participants. It is observed that among the four groups of participants, the group of students got the highest mean score for the two questionnaires of the two brochures. For the shabu questionnaire, students got a mean of $64.3 \%$, while for the marijuana questionnaire, $65 \%$. The unemployed group, however, got the lowest scores for both of the brochures. In terms of the questionnaire on the brochure on shabu, the unemployed scored 39\%, while for the questionnaire on the brochure on marijuana, they scored $46.7 \%$. 
It is observed from the table above that the mean scores of the group of students and group of rehabilitation patients fall under the instructional or assisted level, while the mean scores of the group of employed and unemployed can be categorized as frustration level. With these observable findings, the two existing brochures are not that comprehensible to each of the group of participants.

Looking at the scores of each group of the participants, the students gained the highest scores among the participants who answered the questionnaires. It is claimed that one possible reason for this is the strengthening of the drug education starting when President Rodrigo Duterte stepped into his presidency. The Department of Education (DepEd) has fortified its mission of enhancing the National Drug Education Program (NDEP) in all schools whether public or private from elementary to high school levels. Moreover, DepEd strengthens the program by establishing the Barkada Kontra Droga Chapters in schools, enhancing information communication about drug abuse, and supporting the activities as planned by NDEP coordinators (Department of Education, 2017). Similarly, the Commission on Higher Education (CHED) has approved of the mandatory drug testing of higher education institutions (HEIs) among its students which also encompasses "drug education or awareness, prevention and control initiatives that will promote a drug-free campus" (CHED, 2017).

The group of students was followed by the group of rehabilitation patients who got to the assisted level as well. It is noteworthy that it was discovered that the rehabilitation patients used their experiences and background knowledge in answering the brochures, which made it one possible reason that these participants got to the assisted level. This is further strengthened by the studies of Rumelhart (1980), Carrell (1981), and Hudson (1982) showing that the background knowledge or schema, and the experiences of the readers help in comprehending or understanding the documents that they are using. After the interview with the rehabilitation patients, it was discovered that some of the rehabilitation patients made use of their existing knowledge about the illegal drugs to answer the questionnaires.

The varying scores of the different groups of participants only indicate that the two existing brochures are not that comprehensible to the different groups of participants because one of the factors, as it is claimed, is their differences in age. Daneman and Hannon (2009) have investigated the changes in comprehension as age progresses. This means that as a person grows older, his or her abilities to retain new information and understand a certain text are affected. Therefore, not all the participants were able to grasp or comprehend the texts because of their differences in age.

To further validate the results of the comprehensibility of the two brochures as shown above, the difficulty index of the items of the two questionnaires is further elaborated below. 
The Difficulty Index of the MCQ of All the Participants on the Brochures on Shabu and Marijuana

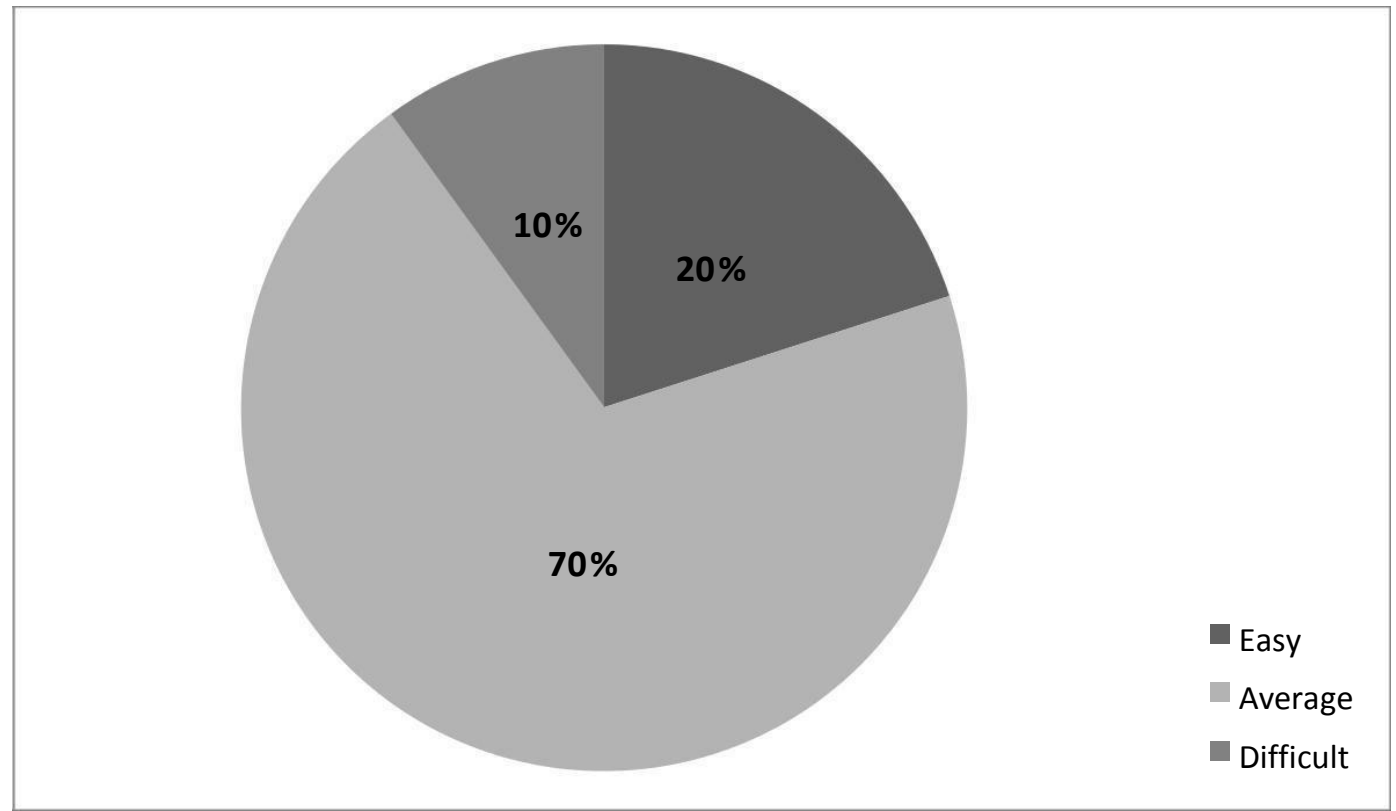

Figure 1. Percentage of the Participants' Difficulty Index of the MCQ on the Brochure on Shabu

The figure above shows that $10 \%$ of the 10 -item questionnaire on the brochure on shabu was difficult for all of the participants, while $20 \%$ of the 10 -item questionnaire was easy for all of the participants. The difficult item for all the participants is item number 4 , while the easy items for them are item numbers 1 and 2 .

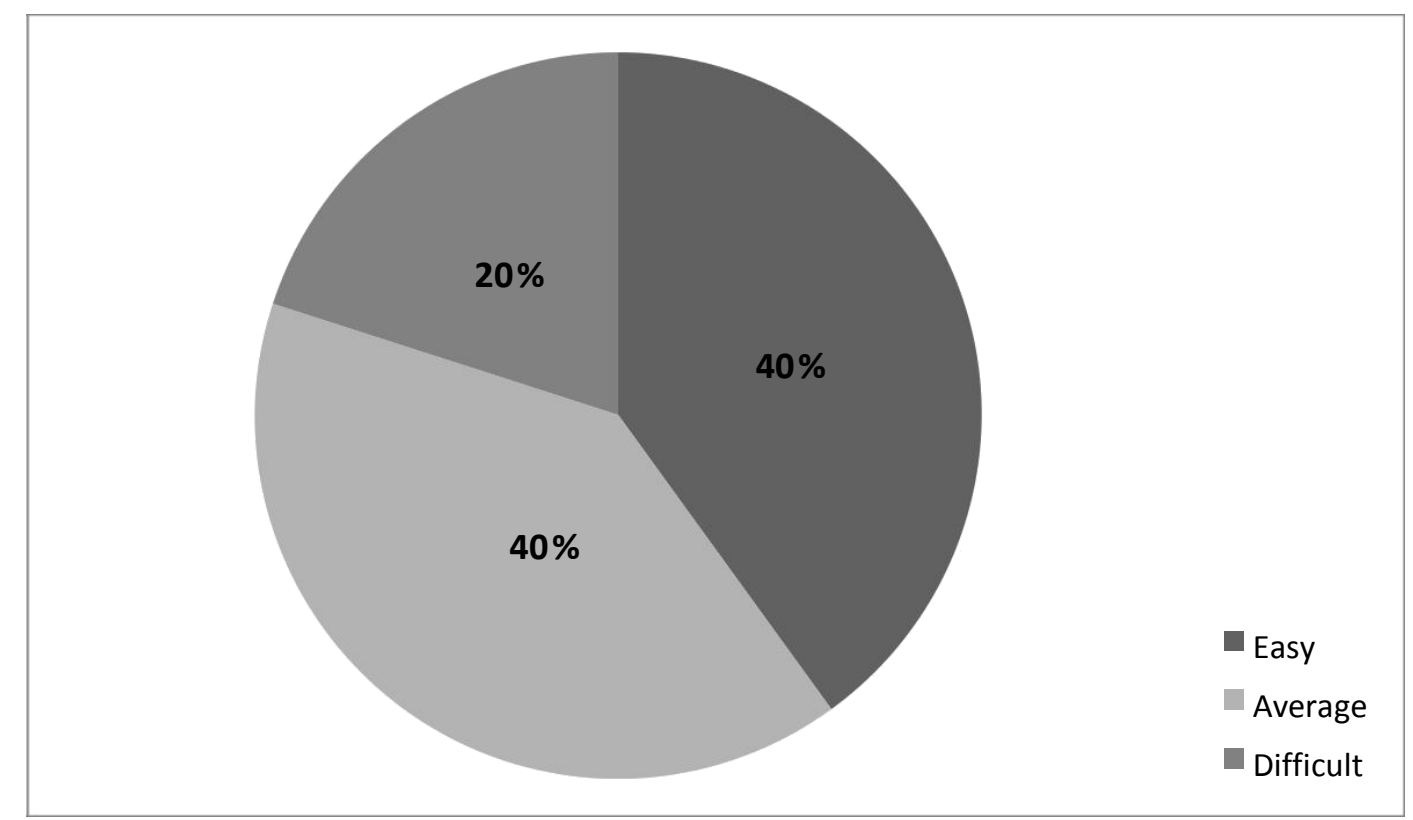

Figure 2. Percentage of the Participants' Difficulty Index on the Brochure on Marijuana 
The figures presented above uncover that most of the items are average for the participants to answer, while there are occurrences of easy and difficult items. It should be noted, however, that for all the group of participants, item numbers 1 and 2 for the MCQ on the brochure on shabu were easy for them to answer since these items appeal to the lower order thinking skills of the readers in a way that they only needed to spot and identify the answer. For the difficult item, item number 4 was observed to be difficult for all of the participants. Although item number 4 also appealed to the lower order thinking skills of the readers, it was a difficult item for all of the participants because one of the possible reasons for this is that 92 participants or $76.67 \%$ had a hard time distinguishing the difference between the physical changes and behavioral changes as their answers to this item was related to the behavioral changes. This is brought by the fact that the titles of the subsections of the brochure on shabu contained technical terms (physiological) and unfamiliar vocabulary (adverse).

In terms of the brochure on marijuana, two items namely item numbers 3 and 9 were found to be difficult for all of the participants. First, for item 3, though it appealed to the lower order thinking skills of the participants, it was still considered difficult because the subsection of the brochure where the answer is found contains an unfamiliar vocabulary (resin) in which participants were unable to understand. Second, item 9, which is a situational item, was found to be difficult for all of the participants since the information pertaining to this item was presented within paragraphs of information which made it difficult to be spotted by the participants.

\section{Lexical Features}

Speaking in terms of lexical features, the two brochures are heavily loaded with technical terms or jargons and words that are not typically used, heard or encountered in the daily interactions of the prospective participants. Below are sample information from the two existing brochures that contain technical terms and unfamiliar vocabulary. The technical terms and unfamiliar vocabulary are underlined for emphasis.

\section{A. Shabu}

GENERAL FACTS

Methamphetamine hydrochloride, a type of amphetamine is also known as "poor man's cocaine.'

\section{PHYSIOLOGICAL EFFECTS}

SOURCE

It has been reported that there are clandestine laboratories...

LONG TERM EFFECTS

...if administered intravenously can lead to psychosis, result to schizophrenia, ... Chronic snorters may suffer from severe irritation of the nasal passages and at times may develop tissue perforation of the nasal septums...

B. Marijuana

WHAT IS THE PRINCIPAL PSYCHOACTIVE COMPONENT OF MARIJUANA? 
The mind altering component is the delta-9-tetrahydro-cannabinol (also referred to as the delta-9-THC) which is concentrated in the resin.

\section{ADVERSE EFFECTS OF CHRONIC OR LONG TERM USE OF MARIJUANA}

- ...cognitive functioning particularly mathematical skills, reading and verbal

- comprehensive skills

- Symptoms of mental illness (psychosis) is exacerbated...

Participants found it difficult to comprehend some of the information from the brochures because of the presence of technical terms and unfamiliar words.

R-16: "Slight ko lang po naintindihan yung brochure. Hehehehe!...Actually, marami po teh eh. ... ito..ito po..physiological... hmmm ... feel ko ano po yan eh..ah.. harmful?" (I only understood it slightly. Hehehehe!... Actually, there are many [terms] eh. [Like]

This..this one.. physiological... Hmmm.. I feel like it means harmful?)

Such remark conforms to the study conducted by Yorio (1971) showing that one of the main problems of foreign language learners (i.e. Spanish) in reading an English text is its vocabulary in which these learners are unfamiliar with because they had not encountered these words (p.109).

\section{Syntactic Features}

Aside from the high use of technical terms and unfamiliar vocabulary, and absence of second person pronoun, it should also be noted that high use of passive voice could have also accounted for the difficulty in understanding the two existing brochures. A sample excerpt is presented below:

"This chemical substance is being smuggled into the country by drug traffickers." "It has been reported that there are clandestine laboratories in the Philippines suspected of manufacturing this substance."

Sentences set in agentless passive voice are said to contribute to sentence complexity and difficulty (Scott, 2009; Shapiro \& Thompson, 2007) and thus, many readers such as English as a Second Language (ESL) readers are beset with problems comprehending texts which results in "significant communication breakdown" (Lomaglio \& Robinson, 1985, p. 26). For this reason, the Federal Plain Language (2011) and other Plain Language advocates (Cutts, 2009; Garner, 2001) have pushed for the use of active voice to aid readers understand the text easily.

The Document Design Features that Accounted for Difficulty in Understanding the Brochures 


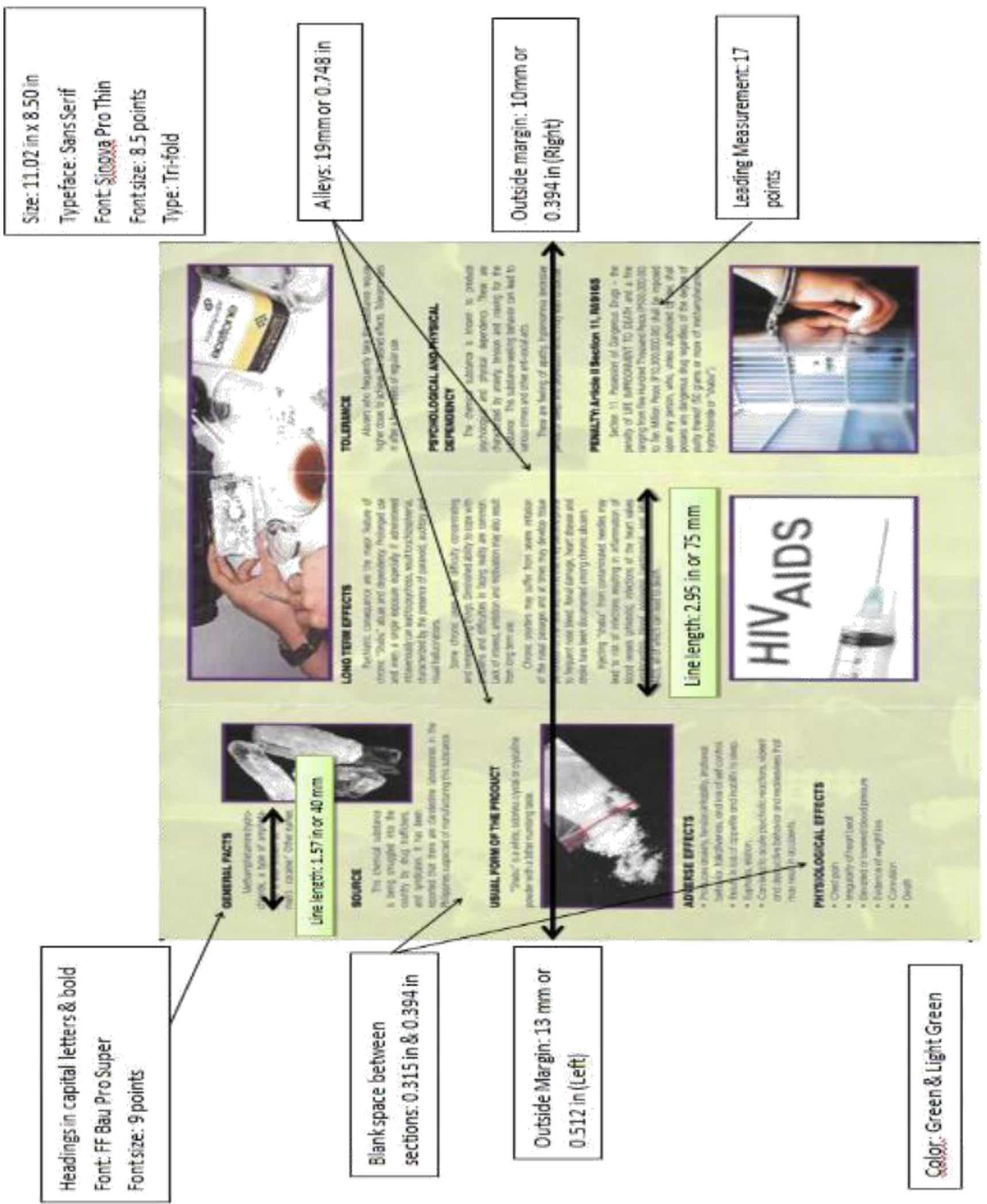

Figure 3. Document Design Features of the Brochure on Shabu 


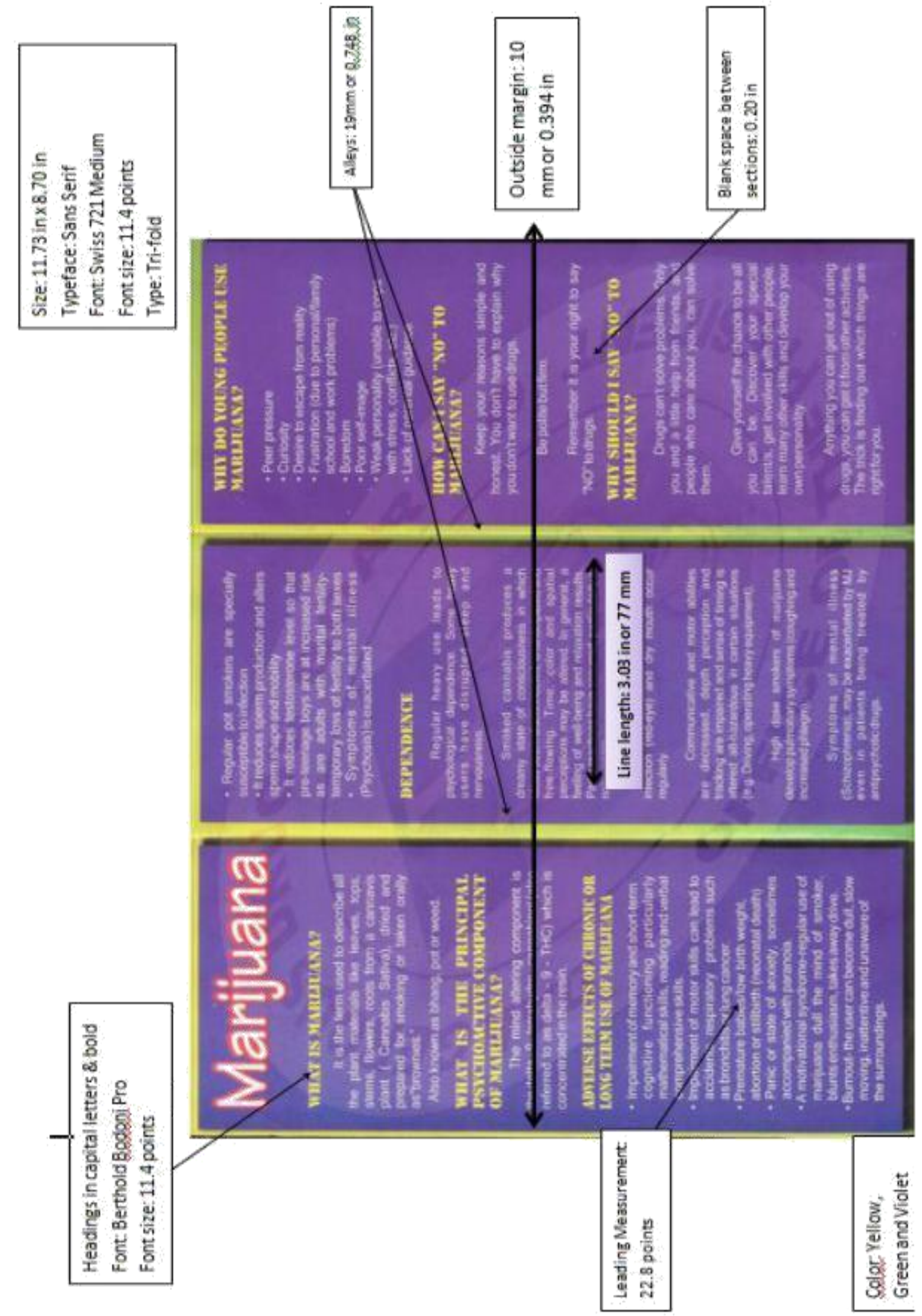

Figure 4. Document Design Features of the Brochure on Marijuana 
Figure 3 shows the document design features of the existing brochure on shabu. It can be observed that there are some violations of document design. First, the body text is set at 8.5 points, a little smaller, as against the standard guideline of 9 points. Additionally, the pictures present on the brochure are pixilated in which it is a sign that the images are of low quality or stretched. It is also observed that some sections of the brochures are not presented in bullet forms in which short sentences are crammed together in one paragraph. Headings of the brochure are set in all capital letters violating the guideline of using upper and lower case letters. Setting texts at all capital letters contribute to slow reading rate of about 13 to 20 percent (Breland \& Breland, 1944 as cited in Schriver, 1997). It has been studied that the reading speed of a material is bound to be at its optimal when there is a use of upper and lower case letters (Poulton, 1967 as cited in Schriver, 1997).

Figure 4 shows the document design features of the brochure on marijuana. It is observed that its color obviously violates the guideline for color schemes. The color combination of the brochure is violet and green which affects the legibility, attraction of the brochure, and its ease of reading. The background of the brochure is colored, while the headings are also colored yellow-green. This is a problematic document design feature of the brochure since it violates the guideline that using a colored text should not be combined with a colored background. The text color is also set in white color violating the rule of using black in order to easily read the text.

In addition, the headings are likewise set in all capital letters which contribute to slow reading rate as mentioned earlier.

To further evaluate the two existing brochures, the participants were asked to rate the document design of the brochures.

\section{Table 9. Participants' Document Design Evaluation of the Brochure on Shabu}

Where G- Good; NG- Not Good; and VG- Very Good

\begin{tabular}{llllllllllll}
\hline Participants & $\mathbf{1}$ & $\mathbf{2}$ & $\mathbf{3}$ & $\mathbf{4}$ & $\mathbf{5}$ & $\mathbf{6}$ & $\mathbf{7}$ & $\mathbf{8}$ & $\mathbf{9}$ & $\mathbf{1 0}$ & $\mathbf{1 1}$ \\
\hline Students & VG & VG & VG & G & VG & VG & VG & VG & VG & VG & VG \\
Employed & NG & G & G & NG & G & G & NG & G & NG & NG & G \\
Unemployed & G & G & G & G & G & G & G & G & G & G & G \\
Rehab Patients & G & G & NG & NG & G & G & G & G & G & G & G \\
\hline
\end{tabular}

It can be noted that the employed group of participants rated item numbers $1,4,7,9$, and 10 as not good. For the brochure on shabu, the employed participants rated the first item that refers to the font size used in the brochure as not good. This is reflected from the violation that was observed from the existing brochure in which the font size was set 8.5 points, lower than the standard point size of 9. Additionally, the employed participants rated the color of the brochure as not good, which only means that the color of the brochure which is green did not attract the participants. The pictures present on the brochure were also rated as not good. Moreover, two items ( 3 and 4) on the evaluation of the brochure on shabu were rated as not good by the rehabilitation patients. The evaluation of items 3 and 4 reflect the 
War on Drugs: The Readability and Comprehensibility of Illegal Drug Awareness Campaign Brochures

violations of the brochure to present some of the information in short sentences, and to avoid technical terms.

\section{Table 10. Participants' Document Design Evaluation of the Brochure on Marijuana}

Where G- Good; NG- Not Good; and VG- Very Good

\begin{tabular}{llllllllllll}
\hline Participants & $\mathbf{1}$ & $\mathbf{2}$ & $\mathbf{3}$ & $\mathbf{4}$ & $\mathbf{5}$ & $\mathbf{6}$ & $\mathbf{7}$ & $\mathbf{8}$ & $\mathbf{9}$ & $\mathbf{1 0}$ & $\mathbf{1 1}$ \\
\hline Students & VG & VG & VG & G & VG & VG & VG & G & NG & NG & G \\
Employed & G & G & NG & NG & G & G & G & G & G & G & G \\
Unemployed & G & G & G & G & G & G & G & G & G & G & G \\
$\begin{array}{l}\text { Rehab } \\
\text { Patients }\end{array}$ & G & G & G & G & G & G & G & G & NG & G & G \\
\hline
\end{tabular}

Table 10 shows that items 9 and 10 of the evaluation of the brochure on marijuana garnered a rating of not good from the students. Item numbers 9 and 10 which refer to the use of pictures were rated as not good since there were no pictures present in the information to support and help the readers understand the text. Similarly, the rehabilitation patients rated item number 9 as not good.

The employed group of participants rated items 3 and 4 as not good. One reason for this is the crammed combination of short sentences in a number of paragraphs. This was elaborated more by the participants who were interviewed:

E-30: "Mas madali basahin yung naka bullet, pag dating dun sa isang part..yung tungkol dun sa...long term effects, parang nakakatamad na basahin kasi medyo mahaba na." (It's easier to read the ones in bullet form. When it comes to the part on long term effects, it feels like it is already tiring to read because it is quite long.)

The US Center for Medicare and Medicaid Services (2010) emphasize that making use of bullet forms is useful for readers to easily navigate on the portion of the text that is important (p. 29). The use of technical terms on the brochure was also rated not good because of the presence of too many technical and unfamiliar words.

\section{CONCLUSION}

The way people use language affects the intended meanings of certain important information like anti-drug awareness campaigns. In the Philippines, drug addiction has been considered as a national problem that has been given emphasis when President Rodrigo Duterte stepped into his presidency in 2016. Because of this, different government agencies like the Dangerous Drugs Board (DDB) have exerted efforts like distributing drug awareness brochures to combat and prevent illegal drug activities in the country. Because of the alarming issues that the country has regarding illegal drugs abuse, this study assessed and analyzed the readability, comprehensibility and document design of the two brochures on prohibited drugs awareness, which were produced and distributed by DDB. This study made use of Garner, Ning, and Francis' (2011) framework for evaluating patient information leaflets (PILs), and Schriver's (1997) framework for analyzing document design. In order to analyze the readability of the two existing brochures, a text-based tool called Coh-metrix, which was developed by Graesser et al (2004), was utilized in this study. The multiple-choice questionnaires were composed of 10 items that deal with the information found on the 
brochures. There were a total number of 120 participants comprised of 30 students, 30 employed, 30 unemployed, and 30 rehabilitation patients from a rehabilitation center, who were tasked to answer the questionnaires and evaluate the linguistic and document design features of the brochures.

The results of this study showed that, in terms of the readability of the two existing brochures, both brochures were found to be not that readable with a high incidence of nouns (364.865 and 322.645) characterized by high occurrences of technical terms and unfamiliar vocabulary. Moreover, a high incidence of agentless passives (11.261 and 12.024) was observed to cause the low readability of the brochures. Additionally, the prospective audiences of the two existing brochures were found to be on the frustration level and instructional or assisted level of comprehension, which means that the participants were not able to fully comprehend the existing brochures. Furthermore, several violations of the document design framework were observed like the inappropriate use of color combinations (green and violet), short sentences crammed in a number of paragraphs, absence and misuse of pictures that contribute to the confusions of the participants in understanding the texts, and others. Based on the evaluation of the participants, it was observed that the designers' negligence in considering the design features of the document design was also the reason for the low evaluation of certain features such as font size, color, short sentences, and others.

The low readability and comprehensibility, and problematic document design features of the two brochures reflect the need for a unified and standardized measure of creating important documents that are crucial in information dissemination. The government or even private companies should provide standardized manuals, toolkits, or guidelines on how to create and produce a material that is highly readable and comprehensible to the lay people. Furthermore, the results of this study sought to advance and promote technical writing courses in which many employees and employers can benefit from. Additionally, the results of this study calls for a legal basis on the use and promotion of Plain Language to help the laypeople understand the texts that they are using, particularly, those texts that are provided by credible authors or sources like the Philippine government. This paper paves the way for government officials to draft and pass bills, or implement an order for the use of plain language since having a legal basis for it is necessary to strengthen the advocacy of the Plain Language Movement. Additionally, this paper is a call for the government agencies like DDB to develop materials that are audience specific, and not just for the general public to be consumed. This has been strengthened by the results in which there were differences in the needs, evaluation, and understanding of the participants that were observed from the results. Another alternative for creating efficient documents such as the anti-illegal drugs awareness campaign brochures may be the use of the Filipino language in presenting information. Moreover, government agencies can produce important information such as antiillegal drugs awareness campaign using both the English and Filipino language as the main intention of such documents is to communicate and be read by different Filipinos from all walks of life. The government agencies and private companies can also make use of local language translation of the brochures as Filipino and English are not the only languages in the country. Translation of documents to local languages can benefit many people residing from provinces whose local language is not Tagalog or English.

\section{REFERENCES}

Allen, D.,Crossley, S., \& NcNamara, D. (2011). Text readability and intuitive simplification: A comparison of readability formulas. Reading in a Foreign Language, 23(1), 84-101. 
Al-Ghamdi, N., Almansoob, N., \& Alrefaee, Y. (2019). Pragmatic Failure in the Realization of the Speech act of Responding to Compliments among Yemeni EFL Undergraduates. 3L: Language, Linguistics, Literature. 25(4), 227-240. doi:10.17576/31-2019-2504-14

Beck, I., McKeown, M., \& Kucan, L. (2002). Bringing words to life. New York: The Guilford Press.

Benjamin, R. (2012). Reconstructing readability: Recent developments and recommendations in the analysis of text difficulty. Educational Psychology Review, 24(1), 63-88.

Bernhardt, S. A. (1986). Seeing the text. College Composition and Communication, $37(1), 66-78$.

Bertrand, A. \& Cebula, J. (1980). Tests, measurement, and evaluation: A developmental approach. USA: Addison-Wesley.

Bradley, B., Singleton, M \& Li Wan Po, A. (1994). Readability of patient information leaflets on over-the-counter (OTC) medicines. Journal of Clinical Pharmacy and Therapeutics, 19(1), 7-15.

Cai, Z., Graesser, A. C., Louwerse, M. M., \& McNamara, D. S. (2004). Coh-Metrix: Analysis of text on cohesion and language. Behavior Research Methods, Instruments, \& Computers, 36(2), 193-202.

Carrell, P. (1981). Content and formal schemata in ESL reading. TESOL Quarterly, 21(3), 461- 481.

Commission on Higher Education. (2017) National public consultation on the proposed policies, guidelines and procedures for drug testing as a requirement for incoming and continuing students in higher education institutions (HEIS). Retrieved from http://ched.gov.ph/wpcontent/uploads/2017/10/National-Public-Consultation-onthe-Proposed-PoliciesGuidelines-and-Procedures-for-Drug-Testing-as-aRequirement-for-Incoming-andContinuing-Students-in-Higher-EducationInstitutions-HEIs.pdf

Crossley, S., Dufty, D., McCarthy, P., \& NcNamara, D. (2007). Toward a new readability: A mixed model approach. Proceedings of the 29th Annual Conference of the Cognitive Science Society, 197-202.

Cutts, M. (2009). Oxford guide to plain English. Oxford: Oxford University Press.

Daneman, M. \& Hannon, B. (2009). Age-related changes in reading comprehension: An individual-differences perspective. Experimental Aging Research: An International Journal Devoted to the Specific Study of the Aging Process, 35(4), 432-456.

Dangerous Drugs Board. (2013, May 21). Preventive education. Retrieved October 16, 2017, from https://www.ddb.gov.ph/component/content/category/27preventive-education

Dubay, W. (2004). The principles of readability. Retrieved from http://www.impactinformation.com/impactinfo/readability02.pdf

Filby, N. \& Olson, D. (1972). On the comprehension of active and passive sentences. Cognitive Psychology, 3(3), 361-381. Retrieved from http://linkinghub.elsevier.com/retrieve/pii/0010028572900138 
Federal Plain Language (2011). Federal plain language guidelines, pp. 1-112.

Francis, D. \& Hester, S. (2004). An invitation to ethnomethodology: Language, society, and interaction. London, United Kingdom: Sage Publications.

Garner, B. A. (2001). Legal writing in plain English: A text with exercises. USA: University of Chicago Press.

Hannan, M., Trivedi, A., \& Trivedi, H. (2014).Readability and comprehensibility of over thecounter medication labels. Renal Failure, 473-477.

Lintao, R. (2015). Simplifying a Philippine consumer-finance contract : Towards the development of a user-comprehensible, readable and legally acceptable document. (Unpublished).

Lintao, R. \& Madrunio, M. (2015). Status: It's complicated?! Analyzing the comprehensibility of a Philippine consumer-finance contract. International Journal of Legal English, 3(1), 27- 45.

LoMaglio, L. J., \& Robinson, V. J. (1985). The impact of passive voice on reading comprehension. IEEE Transactions on Professional Communication, 28(4), 26-27.

Marnell, G. (2008). Measuring readability. Retrieved from https://www.abelard.com.au/readability\%20statistics.pdf

McNamara, D. S., \& Magliano, J. (2009). Chapter 9: Toward a comprehensive model of comprehension. Psychology of Learning and Motivation - Advances in Research and Theory, 51, 297-384. DOI: 10.1016/S0079-7421(09)51009-2.

Mykhailova, O.V. (2012). The main characteristics of legal English [PDF]. Retrieved from dspace.univer.kharkov.ua/bitstream/123456789/7033/2/law_lecture.pdf

National Institutes of Health.(n.d.). Plain language at NIH. Retrieved from https://www.nih.gov/institutes-nih/nih-office-director/officecommunications-publicliaison/clear-communication/plain-language

Omanson, R. C. (1985). Knowing words and understanding texts. New Directions for Child and Adolescent Development, 35 - 53.

Perfetti, C. (2007). Reading ability: Lexical quality to comprehension. Scientific Studies of Reading, 11(4), 357-383.

Philippine Drug Enforcement Agency. (n.d). PDEA Cares: Briefer on the Launching of "Buboy". Retrieved from http://pdea.gov.ph/pdea-cares

Plain Language. (n.d.). Short definition of plain language. Retrieved from https://www.plainlanguage.gov/about/definitions/short-definition/ 
Quismoro, E. (2018, February 8). House committee brings drug campaign to schools. The Manilla Bulletin. Retrieved from https://news.mb.com.ph/2018/02/08/housecommitteebrings-drug-campaign-to-schools/

Rumelhart, D.E. (1980). Schemata: The building blocks of cognition. Retrieved from https://www.colorado.edu/physics/EducationIssues/zwickl/Resources/Rumelhart $\% 20$ Sch emata-The\%20building\%20blocks\%20of\%20cognition.PDF

Schriver, K. (1997) Dynamics in Document Design. Toronto, Canada: Wiley Computer Publishing.

Scott, C.M. (2009).A case for the sentence in reading comprehension. Language Speech and Hearing Services in Schools, 40, 184-191.

Strathmann, S. (1993). Testing reading comprehension. ELT Journal, 33(4), 304-306. Retrieved from http://eltj.oxfordjournals.org/

Tiersma, P.M. (1999). Legal language. Chicago: Chicago University Press.

Thompson, C. K., \& Shapiro, L. P. (2007). Syntactic complexity in treatment of sentence deficits. American Journal of Speech-Language Pathology, 16, 1- 39.

Trudeau, C. (2016). Plain language in healthcare: What lawyers need to know about health literacy. Michigan Bar Journal, 10, 36-39.

U.S Center for Medicare and Medicaid Services. (2010). TOOLKIT for making written material clear and effective. Department of Health and Human Services.

Williams, C. (2011). Legal English and plain language: An update. ESP Across Cultures, $8,139-151$.

Yorio, C. A. (1971). Some sources of reading problems for foreign- language learners. Language Learning, 21(1), 107-115.

Yassin, A. A., Razak, N. A., \& Maasum, N. R. M. (2019). Investigating the Need for Computer Assisted Cooperative Learning to Improve Reading Skills Among Yemeni University EFL Students: A Needs Analysis Study. International Journal of Virtual and Personal Learning Environments (IJVPLE), 9(2), 1531 . 


\section{$\underline{\text { AUTHORS'BIOS }}$}

Fermina Bernabe Vergara finished her BA in English Language Studies degree (Summa cum Laude) at the University of Santo Tomas (UST) in 2018. Right after graduation, she participated in the Language Assistant Program sponsored by the Spanish Government in Toledo, Spain. She is now an English Teacher at the UST Senior High School.

Rachelle Ballesteros-Lintao, Ph.D. is a professor of English at the University of Santo Tomas (UST). She is the incumbent Chair of the UST Department of English. She has published papers and presented in various conferences in line with her research interests in forensic linguistics, discourse analysis, language education, and language and technology. She is the Country Representative of Clarity, an international organization that promotes plain language in legal documents. 